\title{
The effect of the physiological reserve surrogate characteristics on non-airway extubation failure in patients with pneumonia with high Burns Wean Assessment Program scores
}

\author{
Rakan M. AlQahtani ${ }^{1, \star}$, Yasmeen Khalaf Altaymani ${ }^{2}$, Saud Ali Aljasir ${ }^{2}$, \\ Bader Abdulaziz Zawawi ${ }^{1}$, Hisham Khaled Algossy ${ }^{1}$, Khalid Waleed Alhusainan ${ }^{1}$, \\ Mohammed Yousef Alyousef ${ }^{1}$, Mohammed Ibrahim Alarifi ${ }^{1}$, Abdalrhman Al saadon ${ }^{1}$
}

\author{
${ }^{1}$ Department of Critical Care Medicine, \\ College of Medicine, King Saud \\ University, 11451 Riyadh, Saudi Arabia \\ ${ }^{2}$ Department of Critical Care Medicine \\ and Respiratory Care Services, King \\ Khaled University Hospital, 123726864 \\ Riyadh, Saudi Arabia \\ *Correspondence \\ arakan@ksu.edu.sa \\ (Rakan M. AlQahtani)
}

\begin{abstract}
Objectives: A successful weaning prediction score could be a useful tool to predict nonairway extubation failure. However, it may carry some challenges without considering the effect of the physiological reserve on the sustainability of extubation. This study investigated the possible correlation between the physiological reserve surrogate characteristics including acute, baseline, and biochemical patients' factors and nonairway extubation failure in patients with pneumonia.

Methods: A retrospective cohort study at two academic teaching hospitals was conducted between January 2019 and January 2020 with patients with pneumonia requiring invasive mechanical ventilation and with Burns Wean Assessment Program (BWAP) scores equal to or exceeding 50. Acute clinical, biochemical, and baseline characteristics were collected for both successful and failed non-airway extubation patients.

Results: Among 313 patients, the mean age was $63.63 \pm 10.44$ years and most of the patients were males $(60.7 \%)$. The median invasive mechanical duration was 7 days [Interquartile range (IQR): 5-12], the median length of ICU stay was 12 [IQR: 6-23] and the in-hospital mortality was $16.9 \%$. Among this cohort of patients with pneumonia, $37.7 \%$ had non-airway extubation failure. Multivariate logistic regression analyses showed that higher CURB-65 score, longer duration of invasive mechanical ventilation, hemodynamic instability, healthcare-associated pneumonia, older men, history of diabetes mellitus, history of cardiac disease, hypophosphatemia, hypocalcemia, and higher admission serum sodium were associated with increased risk of non-airway extubation failure in patients with pneumonia with high BWAP score.

Conclusion: A distinct successful weaning score for patients with pneumonia that considers patients' acute clinical, biochemical, and baseline characteristics may be effective, and these factors could be reflective of the underlying physiological reserve. Sustainability score from IMV rather than weaning score is needed and may be more predictive for the extubation outcome.
\end{abstract}

\section{Keywords}

Extubation failure; Intensive care unit; Mechanical ventilation; Pneumonia; Physiological reserve; CURB-65

\section{Introduction}

Pneumonia is one of the top six causes of death, and $10 \%$ of hospitalized patients with pneumonia require invasive mechanical ventilation (IMV), mainly owing to respiratory failure [1]. The incidence of extubation failure is reported to range $6 \%$ to $47 \%$, while the mortality rate varies between $30 \%$ and $40 \%$ [2-4]. Extubation failure results in increased length of stay in hospitals and intensive care units (ICUs), increased mortality rates in hospitals and ICUs, and increased total hospital costs by an average of 34,000 US dollars [5]. These grave issues demand the identification of predictors and risk factors associated with extubation failure.

Reasons behind reintubation include primary respiratory failure leading to an episode of respiratory distress, congestive heart failure, ineffective cough, aspiration, upper airway 
obstruction, or airway secretion build-up; in addition to new sepsis, acute coronary syndrome surgical complications, and neurological impairment [6]. The plethora of causative factors highlight the uncertainty in the management of clinical difficulties of extubation and ambiguities in the pathophysiological attributes of extubation failure. Extubation failure is defined as reintubation requirement within days or hours after planned extubation $[1,7]$. The time interval varies between 48 hours to 72 hours or seven days [8]. Extubation failure could be airwayrelated, which is the inability to breath without endotracheal tube. Airway extubation failure could be either upper airway obstruction such as post-extubation laryngeal edema or lower airway obstruction such as uncontrollable secretions leading to long collapse or severe bronchospasm in asthma patients. On the other hand, non-airway-related extubation failure, or the inability to breath without respiratory support from IMV, is usually due to pulmonary edema or neuromuscular weakness leading to hypoventilation [9].

Airway extubation failure is usually obvious and can be predicted from a successful weaning prediction tool. However, non-airway extubation failure has so many factors, either related to the disease itself or other preexisting chronic health problems, that are associated with limited physiological reserve [10]. These factors are often overlooked in the assessment of extubation success [11].

Mechanical ventilation owing to pneumonia with unresolved infection is a predictor of extubation failure. However, in general, the requirement of IMV provides life support and decreased respiratory workload, increased arterial oxygenation, and rebalanced ventilation-perfusion ratio, thus contributing to reduced mortality [12]. After partial recovery, patients are liberated from IMV. This discontinuation process comprises two phases: weaning (ventilatory support discontinuation) and extubation (airway discontinuation) [13]. Even in patients who meet weaning criteria with a successful weaning readiness test, extubation failure occurs $10 \%$ to $20 \%$ of the time [11]. Several studies have suggested that the identification of patients capable of spontaneous breathing could reduce the complication rates in extubation. However, even in cases of successful spontaneous breathing trials, extubation failure occurs $15 \%$ of the time, indicating that these tests are an incompetent predictor among high-risk patients, such as patients with pneumonia [14]. Conclusively, the predictors that forecast weaning outcomes cannot accurately envisage extubation failure. Moreover, the predictors of extubation failure-age, comorbidity burden, mental status, cardiac function, serum albumin, fluid balance, hypercapnia, blood urea nitrogen (BUN), and maximal inspiratory pressure - have been studied in a cluster of disorders and may not predict extubation failure in pneumonia, which itself is an independent risk factor for extubation failure [4].

On the other hand, the physiological reserve is an issue that has been usually overlooked in the context of the readiness for extubation that may not necessarily reflect the sustainability after extubation [15]. The physiological reserve is defined as the capability of the body to handle the activity under stress in the context of the pathophysiology of the disease and through the recovery phase of the disease [16]. This is often expressed as a subjective assessment by the treating physician, and hence the clinical judgement is very crucial in estimating the physiological reserve. There is no single validated assessment tool to measure the physiological reserve that could be reflective through the comorbid conditions and the severity of the disease associated acute factors can be utilized as surrogate markers in certain diseases [17]. This fact will be more evident in pneumonia because it is a common cause of IMV requirement in ICU and the severity of the disease also plays an important factor in the difficulty of liberation from IMV [18].

Therefore, there is a definite need to identify the independent predictors of extubation failure in patients with pneumonia, as planned interventions based upon predicted risk are a cornerstone of clinical decisions that impact patients' outcomes [15]. Furthermore, these predictors can be useful markers for determining the physiological reserve which can predict the extent to sustain the liberation from IMV in the recovery phase [19].

We evaluated the parameters that are closely related to the physiological reserve as independent predictors of non-airway extubation failure in patients with pneumonia as opposed to the traditional objective weaning parameters that will predict the success of weaning at the time of extubation without taking into consideration the time factor after extubation and the functional capacity to withstand the need for IMV.

The hypothesis of this study is that early findings and characteristics of the patients with pneumonia upon presentation could be more important predictive tools and more accurate in determining the physiological reserve and more related to the readiness to IMV liberation than using the extubation success assessment checklist alone as predictive value for extubation failure.

\section{Methods}

\subsection{Study design}

A retrospective observational cohort study was conducted between January 2019 and January 2020 at King Saud University affiliated teaching hospitals to identify any physiological or biochemical parameters as independent predictors of early extubation failure in patients with pneumonia. The study design was approved by the Institutional Review Board of the health science colleges at King Saud University (E-19-4221). Records were collected for statistical analysis through an electronic health records system. Samples size (n), considering population size $(\mathrm{N})$ and a margin of error $(\mathrm{e})$, was calculated with Solvin's formula: $\mathrm{n}=\mathrm{N} /\left(1+\mathrm{Ne}^{2}\right)$.

\subsection{Patient population and inclusion and exclusion criteria}

We included all adult (aged $>19$ years) patients with pneumonia requiring IMV who scored $\geq 50$ on the Burns Wean Assessment Program (BWAP) which is considered the cutoff limit of successful weaning [16]. BWAP, which was used and well validated in long-term mechanically ventilated patients that was defined as patients requiring IMV more than 3 days, was also used in this study for the patients with pneumonia 
who required intubation more than 72 hours before screening the patients to help using this validated score. BWAP was validated as good predictive tool if the score is more than 50 . Therefore, we excluded all patients scoring $<50$ on the BWAP or those with acute events not related to the original pneumonia diagnosis or the complications associated with it that led to reintubation (e.g., Myocardial infarction (MI), new sepsis, hospital acquired pneumonia, ventilator associated pneumonia, upper gastrointestinal bleeding, and others). We also excluded those requiring non-invasive ventilation (NIV) after extubation more than 24 hours since it could potentially delay the need for intubation beyond the 72-hour period, those with unplanned self-extubation, those who underwent tracheostomy from the first intubation, or those who underwent palliative one-way extubation.

\subsection{Non-airway extubation failure definition and criteria}

Due to the variability of definition of the extubation failure in the literature and to minimize selection bias and to help enrollment of target patients centered around the physiologic reserve that is necessary to sustain the liberation from IMV for 72 hours and beyond, the data collectors adapted a stepwise approach to help identifying patients with non-airway extubation failure due the inadequate physiologic reserve resulting from the original pneumonia diagnosis [20]. First, the airway extubation failure due to post-extubation laryngeal edema, which is usually happened minutes to hours after the extubation trial, have been excluded. Second, the non-airway extubation failure due to an acute events post extubation not related to the initial pneumonia and the associated complications have been excluded on the chart review. Third, we include the distinct group of patients who had to be reintubated because of the general weakness which was assessed subjectively on the patients charts indicating frailty, which is reflective of inadequate physiologic reserve which contribute to the lack of sustainability from IMV. Successful extubation was defined as the removal of an endotracheal tube for more than 72 hours [8].

\subsection{Extubation procedures}

A spontaneous breathing trial was conducted in case the causes of mechanical ventilation were relieved or alleviated, $\mathrm{PaO}_{2} / \mathrm{FiO}_{2}>150-200$ at $\mathrm{FiO}_{2} \leq 0.4-0.5$ and PEEP $\leq 5-8 \mathrm{~cm} \mathrm{H} \mathrm{H}_{2} \mathrm{O}$, stable hemodynamic, capability of spontaneous breathing patients were extubated in absence of (1) diaphoresis, anxiety, agitation, depressed mental status; (2) increase in accessory muscle activity; (3) $\mathrm{PaO}_{2} \leq 50-60$ mmHg at $\mathrm{FiO}_{2} \geq 0.5$ or $\mathrm{SaO}_{2}<90 \%$; (4) $\mathrm{PaCO}_{2}>50 \mathrm{mmHg}$ or increase in $\mathrm{PaCO}_{2}>8 \mathrm{mmHg}$; (5) $\mathrm{pH}<7.32$ or decrease in $\mathrm{pH}$ of $\geq 0.07$; (6) a respiratory rate $>35$ beats per minute or increased by $\geq 50 \%$; (7) rapid shallow breathing index score $>105$ beats per minute; ( 8 ) heart rate $>140$ beats per minute or increased by $\geq 20 \%$; (9) systolic blood pressure $<90 \mathrm{mmHg}$ or $>180 \mathrm{mmHg}$ or increased by $\geq 20 \%$; and (10) cardiac arrhythmias [21, 22].

\subsection{Data collection}

We collected baseline characteristics including age, sex, body mass index (BMI), history of diabetes mellitus, hypertension, history of chronic lung disease, and history of cardiac disease. Acute factors included admission APACHE II score, type of pneumonia, CURB-65, type of respiratory failure preceding the intubation, concomitant viral illness, and use of steroids. We also included biochemical laboratory measurements at admission including serum sodium $\left(\mathrm{Na}^{+}\right)$, chloride $\left(\mathrm{Cl}^{-}\right)$, bicarbonate $\left(\mathrm{HCO}_{3}{ }^{-}\right)$albumin, $\mathrm{BUN}$, phosphorus $\left(\mathrm{PO}_{4}{ }^{-}\right)$, and corrected calcium $\left(\mathrm{Ca}^{++}\right)$. We also included biochemical lab abnormalities upon admission including hypoalbuminemia, hypophosphatemia, and corrected hypocalcemia.

TA B L E 1. Patients' sociodemographic and medical characteristics $(\mathrm{N}=313)$.

\begin{tabular}{|c|c|c|c|}
\hline & & n $(\%)$ & Mean (SD) \\
\hline \multicolumn{4}{|l|}{ Sex } \\
\hline & Female & $123(39.3)$ & \\
\hline & Male & $190(60.7)$ & \\
\hline Age, years & & & $63.63(10.44)$ \\
\hline \multicolumn{4}{|l|}{ Age group } \\
\hline & $21-43$ years & $10(3.2)$ & \\
\hline & 44-64 years & $173(55.3)$ & \\
\hline & $\geq 65$ years & $130(41.5)$ & \\
\hline
\end{tabular}

Body mass index

\begin{tabular}{|lc}
$<18$ & $22(7)$ \\
\hline $18-24.99$ & $85(27.2)$ \\
$25-29.99$ & $86(27.5)$ \\
$30-34.99$ & $62(19.8)$ \\
$\geq 35$ & $58(18.5)$ \\
\hline
\end{tabular}

History of diabetes

\begin{tabular}{|cc|}
\hline No & $128(40.9)$ \\
\hline Yes & $185(59.1)$ \\
\hline History of hypertension & \\
\hline No & $165(52.7)$ \\
Yes & $148(47.3)$ \\
\hline
\end{tabular}

History of chronic lung disease

$\begin{array}{ll}\text { No } & 245(78.3) \\ \text { Yes } & 68(21.7)\end{array}$

History of cardiac disease

$\begin{array}{lc}\text { No } & 233(74.4) \\ \text { Yes } & 80(25.6)\end{array}$

SD, Standard deviation.

\subsection{Statistical analyses}

Means (M) and standard deviations (SDs) were used to describe the continuous measured variables and the frequency and percentages for categorical variables. The KolmogorovSmirnov test of normality and histograms were used to assess 
Adult patients aged $>19$, with features of pneumonia and respiratory failure requiring IMV for more than 72 hours

$$
(\mathrm{n}=422)
$$

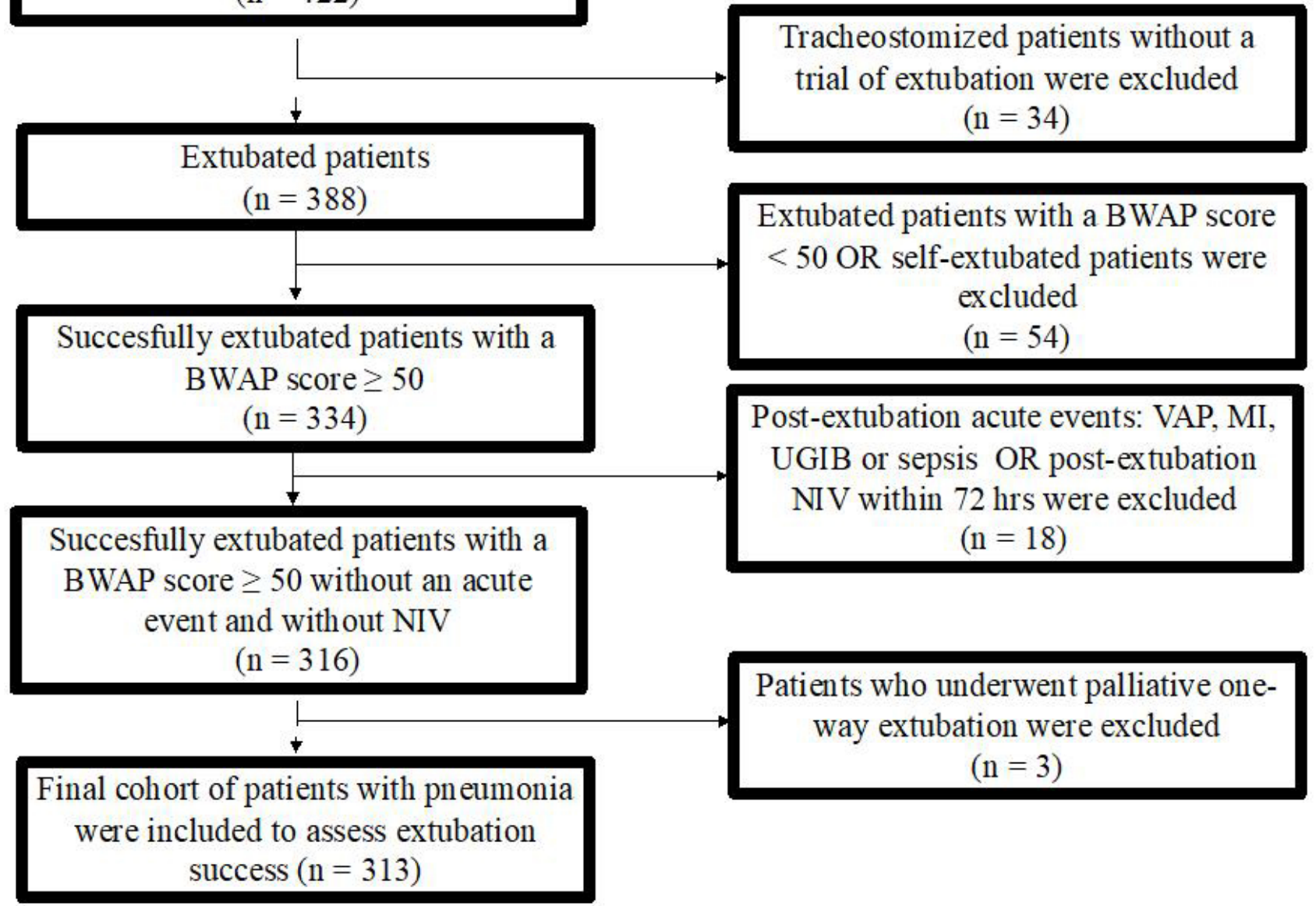

F I G U R E 1. Enrollment of patients with pneumonia to assess extubation success.

IMV, invasive mechanical ventilation; BWAP, the Burns Wean Assessment Program; VAP, ventilator-associated pneumonia; MI, Myocardial infarction; NIV, non-invasive ventilation; UGIB, Upper Gastrointestinal Bleeding; Post extubation new events (events not related to the initial pneumonia or the pneumonia associated complications).

continuous measured variables, and Levene's test was used to assess the homogeneity of variance statistical assumption for continuous variables. Independent samples $t$-tests were conducted to assess the significant mean differences between continuous variables across the levels of binary dichotomous variables, and the Mann-Whitney U non-parametric test was used to assess the mean differences of length of stay and mechanical ventilation durations across the levels of reintubation. Chi-squared tests were used to assess the correlations between categorically measured variables. Multivariate binary logistic regression analyses were conducted to explore the association between patients' sociodemographic and clinical characteristics at admission as well as their past medical history against their odds of failing the extubation process in the ICU. The dependent variable of interest was extubation failure, and the association between these risk factors and reintubation characteristics was expressed with odds ratios (ORs) with 95\% confidence intervals. SPSS version 20 (SPSS Inc., Chicago, IL, USA) was utilized for data analyses, and EXCEL spreadsheets were employed to create figures and depictions. Significance was set at $p<0.05$.

\section{Results}

A total of 422 adult patients aged $>19$ years were admitted with both clinical and radiologic features of pneumonia along with respiratory failure requiring IMV. Thirty-four excluded patients were tracheostomized without extubation. Fifty-four patients were excluded because they had a BWAP score below 50. Sixteen had an acute event not related to the initial diagnosis of pneumonia including ventilator-associated pneumonia, MI, new sepsis, and others or they required NIV more than 24 hours within 72 hours. Three underwent palliative one-way extubation. The final analysis included 313 patients (Fig. 1). A total of 118 patients after the final analysis had non-airway extubation failure, and no patients had airway extubation failure. All enrolled patients with pneumonia diagnosis who have required IMV have been intubated for 4 days and more. 
TA B L E 2. Patients' admission clinical characteristics, and co-variates.

$\mathrm{n}(\%) \quad$ Mean $(\mathrm{SD})^{*}$, median $(\mathrm{IQR})^{* *}$

\section{Pneumonia type}

$\begin{array}{lc}\text { Aspiration } & 44(14.1) \\ \text { Community-acquired } & 172(55) \\ \text { Hospital-acquired } & 97(31)\end{array}$

CURB-65 score at admission, mean (SD)

$4.10(0.67)$

CURB-65 on admission

$\begin{array}{cc}3 & 60(19.2) \\ 4 & 174(55.6) \\ 5 & 79(25.2)\end{array}$

Acute respiratory failure type

Hypoxemic

$190(60.7)$

Hypercapnic

$123(39.3)$

Hemodynamic instability $>24$ hours

$98(31.3)$

Viral concomitant infections

$\begin{array}{lc}\text { No } & 268(85.6) \\ \text { Yes } & 45(14.4)\end{array}$

Non-airway extubation

$\begin{array}{ll}\text { No } & 195(62.3) \\ \text { Yes } & 118(37.7)\end{array}$

Mechanical ventilation duration, days, (median, IQR)

ICU LOS in days (median, IQR)

$7(5-12)$

$12(6-23)$

Hospital LOS in days (median, IQR)

$26(17-37)$

APACHE II score, mean (SD)

$19.28(8.35)$

In-hospital mortality

No

$260(83.1)$

Yes

$53(16.9)$

Admission time lab work

Serum $\mathrm{Na}^{+}, \mathrm{mmol} / \mathrm{L}$, mean (SD)

$138.92(6.19)$

Serum $\mathrm{Cl}^{-}, \mathrm{mmol} / \mathrm{L}$, mean (SD)

25.67 (4.82)

Serum $\mathrm{HCO}_{3}{ }^{-}, \mathrm{mmol} / \mathrm{L}$, mean (SD)

$102.97(7.30)$

High BUN ( $\geq 19 \mathrm{mg} / \mathrm{dL})$

$\begin{array}{ll}\text { No } & 126(40.3) \\ \text { Yes } & 187(59.7)\end{array}$

Persistent hyperlactatemia (lactate $>2$ beyond 24 hours) 27 (8.62)

Admission platelet, $10^{3} / \mu \mathrm{L}$, mean (SD)

$274.1(141.04)$

Serum albumin, $\mathrm{g} / \mathrm{L}$, mean (SD)

$27.37(7.10)$

Hypoalbuminemia $(<25 \mathrm{~g} / \mathrm{L})$

$\begin{array}{lc}\text { No } & 64(20.4) \\ \text { Yes } & 249(79.6)\end{array}$

Serum $\mathrm{PO}_{4}{ }^{-}, \mathrm{mmol} / \mathrm{L}$, mean (SD)

$1.05(0.432)$

Hypophosphatemia $(<0.8 \mathrm{mmol} / \mathrm{L})$

$\begin{array}{ll}\text { No } & 203(64.9) \\ \text { Yes } & 110(35.1)\end{array}$


TA B L E 2. Continued.

\begin{tabular}{lcc} 
& $\mathrm{n}(\%)$ & Mean $(\mathrm{SD})^{*}$, median $(\mathrm{IQR})^{* *}$ \\
$\begin{array}{l}\text { Corrected serum } \mathrm{Ca}^{++} \text {level, mmol/L, mean }(\mathrm{SD}) \\
\text { Hypocalcemia corrected } \mathrm{Ca}^{++}(<2 \mathrm{mmol} / \mathrm{L})\end{array}$ & & $2.11(0.20)$ \\
$\quad$ No & $256(81.8)$ \\
$\quad 57(18.2)$ \\
$\quad$ Yes \\
Use of steroids upon admission \\
$\quad 260(83.1)$ \\
$\quad$ No & $53(16.9)$ \\
\hline
\end{tabular}

CURB-65, confusion, urea $>7 \mathrm{mmol} \cdot L-1$, respiratory rate $\geq 30 \cdot \mathrm{min}-1$, low blood pressure, and age $\geq 65$ years; $\mathrm{Na}^{+}$, sodium; $\mathrm{Cl}^{-}$, chloride; $\mathrm{HCO}_{3}{ }^{-}$, Bicarbonate; $\mathrm{BUN}$, blood urea nitrogen; $\mathrm{PO}_{4}^{-}$, phosphorus; $\mathrm{Ca}^{++}$, calcium; LOS, length of stay;

*SD, standard deviation; **IQR, interquartile range.

\subsection{Baseline characteristics}

Table 1 displays patients' sociodemographic and medical characteristics. Most of the final cohorts were males (60.7\%), aged between 44 and 64 years old (55.2\%). Patients with history of DM, HTN, chronic lung disease, and cardiac disease were $59.1 \%, 47.3 \%, 21.7 \%$, and $25.6 \%$, respectively. Patients' BMI was also computed and classified, and obese patients were $38.3 \%$ of the enrolled patients.

\subsection{Acute clinical factors}

The mean APACHE II score on admission was 19.28 \pm 8.35 , and in-hospital mortality was $16.9 \%$ (Table 2). The results also indicated that $14.1 \%$ of the patients had presented with aspiration pneumonia, while $55 \%$ presented with communityacquired pneumonia and $31 \%$ had hospital-acquired pneumonia. The mean CURB-65 was 4.1 out of $5(\mathrm{SD}=0.67)$. More than half $(55.6 \%)$ of the admitted patients had a CURB65 of 4. Further, $60.7 \%$ of the patients were intubated owing to hypoxemic respiratory failure, while $39.3 \%$ had developed hypercapnic respiratory failure. Moreover, $31.3 \%$ had escalating vasopressor requirements beyond the 24-hour period. However, considering all patients scored $\geq 50$ points on the BWAP tool, which indicated a high likelihood of successful weaning from the mechanical ventilator and extubation, the analysis revealed that $37.7 \%$ of the patients had failed extubation within 72 hours and the median (IQR) mechanical ventilation duration was 7 (5-12) days. Nonetheless, the median (IQR) length of ICU and hospital stay were 12 (6-23), and 26 (17-37) days, repectively. In addition, $16.9 \%$ of the sample had received steroid therapy upon admission.

\subsection{Biochemical factors}

The mean serum $\mathrm{Na}^{+}$among patients upon arrival was 138.92 $\pm 6.2 \mathrm{mmol} / \mathrm{L}$, and the mean serum $\mathrm{Cl}^{-}$was $102.97 \pm 7.3$ $\mathrm{mmol} / \mathrm{L}$. The mean serum $\mathrm{HCO}_{3}{ }^{-}$was $25.67 \pm 4.82 \mathrm{mmol} / \mathrm{L}$, and $59.7 \%$ of the patients presented with a BUN that was higher than $19 \mathrm{mg} / \mathrm{dL}$. Moreover, the mean serum albumin was $27.37 \pm 7.1 \mathrm{~g} / \mathrm{L}$, and $79.6 \%$ had hypoalbuminemia (albumin level $<25 \mathrm{~g} / \mathrm{L}$ ) upon arrival at the ICU. The mean serum $\mathrm{PO}_{4}{ }^{-}$ was $1.05 \pm 0.43 \mathrm{mmol} / \mathrm{L}$, and $35 \%$ of the patients presented with hypophosphatemia $\left(\mathrm{PO}_{4}{ }^{-}<0.8 \mathrm{mmol} / \mathrm{L}\right)$ at admission. The mean corrected $\mathrm{Ca}^{++}$was $2.11 \pm 0.2 \mathrm{mmol} / \mathrm{L}$, and $18.2 \%$ were hypercalcemic $\left(\mathrm{Ca}^{++}<2 \mathrm{mmol} / \mathrm{L}\right)$. The hematological lab revealed that platelet count in this cohort was $274 \pm 140.04$ $10^{3} / \mu \mathrm{L}$ and persistent hyperlactatemia $(>2 \mathrm{mmol} / \mathrm{L}$ ) beyond 24 hours in $8.62 \%$.

\subsection{Bivariate and multivariate regression analysis}

To clarify why the patients with pneumonia failed the extubation process, we explored patients' extubation success/failure and any significant associations with their measured sociodemographic or medical characteristics (Table 3). There was no significant difference in the mean APACHE II score (SD) between who failed extubation compared to those who had successful extubation [20.3 (8.45) vs. 18.6 (7.27); $p=0.064]$. There was also no significant difference in in-hospital mortality between both groups [14.4\% vs. $18.5 \%(p=0.353)]$. However, there was a significant association between patients' sex and reintubation, as men were significantly more likely to have extubation failure than women $(p=0.001)$. Furthermore, the patients who failed the extubation were significantly older with the mean age of $65.9 \pm 8.85$ years vs. $62.26 \pm 11.1$ years for those who had a successful extubation; $p=0.003$. However, patients' age group was not significantly correlated with their reintubation outcome $(p=0.403)$. BMI and patients' medical history of DM, and HTN were not correlated with extubation failure risk.

Patients with a history of chronic lung disease or cardiac disease were significantly more likely to have failed the extubation process compared to their counterparts $(p=0.037$ and $p<$ 0.001 , respectively). Unsurprisingly, patients who underwent reintubation had significantly longer median (IQR) duration on mechanical ventilation before the attempt of extubation compared to those who did not have extubation failure [12 (613) days vs. 6 (4-9) days; $p<0.001)]$. Moreover, patients who failed to be extubated stayed significantly longer median duration (IQR) in the ICU than those whose endotracheal tube was successfully removed [19 (11-37) days vs. 11 (5-16) days; $p<0.001]$ and longer median hospital stay [50 (28-122) days vs.18 (16-26) days; $p<0.001$ ] (Table 3). 
TA B L E 3. Bivariate analysis concerning patients' extubation failure.

\begin{tabular}{|c|c|c|c|c|}
\hline & \multicolumn{4}{|c|}{ Failed the extubation process, $\mathrm{n}(\%)$} \\
\hline & No $=195(62.3 \%)$ & Yes $=118(37.7 \%)$ & Test & $p$ \\
\hline \multicolumn{5}{|l|}{ Sex } \\
\hline Female & $90(46.2)$ & $33(28)$ & $\chi^{2}(1)=10.20^{*}$ & 0.001 \\
\hline Male & $105(43.8)$ & $85(72)$ & & \\
\hline Age, mean (SD) & $62.26(11.10)$ & $65.90(8.85)$ & $\mathrm{t}(311)=3.026^{* *}$ & 0.003 \\
\hline $21-43$ years & $8(4.1)$ & $2(1.7)$ & $\chi^{2}(2)=1.82$ & 0.403 \\
\hline 44-64 years & $104(43.3)$ & $69(58.5)$ & & \\
\hline$\geq 65$ years & $83(42.6)$ & $47(39.8)$ & & \\
\hline \multicolumn{5}{|l|}{ Body mass index } \\
\hline$<18$ & $14(7.2)$ & $8(6.8)$ & $\chi^{2}(4)=4.64$ & 0.326 \\
\hline $18-24.99$ & $47(24.1)$ & $38(32.2)$ & & \\
\hline $25-29.99$ & $51(26.2)$ & $35(29.7)$ & & \\
\hline $30-34.99$ & $42(21.5)$ & $20(16.9)$ & & \\
\hline$\geq 35$ & $41(21)$ & $17(14.4)$ & & \\
\hline \multicolumn{5}{|l|}{ History of diabetes } \\
\hline No & $79(40.5)$ & $49(41.5)$ & $\chi^{2}(1)=0.031$ & 0.86 \\
\hline Yes & $116(59.5)$ & $69(58.5)$ & & \\
\hline \multicolumn{5}{|l|}{ History of hypertension } \\
\hline No & $104(53.3)$ & $61(51.7)$ & $\chi^{2}(1)=0.10$ & 0.778 \\
\hline Yes & $91(46.7)$ & $57(48.3)$ & & \\
\hline \multicolumn{5}{|l|}{ History of chronic lung disease } \\
\hline No & $160(82.1)$ & $85(72)$ & $\chi^{2}(1)=4.34$ & 0.037 \\
\hline Yes & $35(17.9)$ & $33(28.0)$ & & \\
\hline \multicolumn{5}{|l|}{ History of cardiac disease } \\
\hline No & $164(84.1)$ & $69(58.5)$ & $\chi^{2}(1)=25.40$ & $<0.001$ \\
\hline Yes & $31(15.9)$ & $49(41.5)$ & & \\
\hline IMV duration in days, (median, IQR) & $6(4-9)$ & $12(6-13)$ & $\mathrm{U}(313)=17183 * * *$ & $<0.001$ \\
\hline ICU LOS in days, (median, IQR) & $11(5-16)$ & $19(11-37)$ & $U(313)=16269$ & $<0.001$ \\
\hline Hospital LOS in days, (median, IQR) & $18(16-26)$ & $50(28-122)$ & $\mathrm{U}(313)=11505$ & $<0.001$ \\
\hline \multicolumn{5}{|l|}{ In-hospital mortality } \\
\hline No & $159(81.5)$ & $101(85.6)$ & $\chi^{2}(1)=0.859$ & 0.353 \\
\hline Yes & $36(18.5)$ & $17(14.4)$ & & \\
\hline \multicolumn{5}{|l|}{ Hemodynamic instability $>24$ hours } \\
\hline No & $149(76.4)$ & $66(55.9)$ & $\chi^{2}(1)=14.33$ & 0.0002 \\
\hline Yes & $46(23.6)$ & $52(44.1)$ & & \\
\hline APACHE II score, mean (SD) & $18.6(7.27)$ & $20.3(8.45)$ & $\mathrm{t}(311)=1.88$ & 0.064 \\
\hline \multicolumn{5}{|l|}{ Admission time lab work } \\
\hline Serum $\mathrm{Na}^{+}, \mathrm{mmol} / \mathrm{L}$ mean $(\mathrm{SD})$ & $137.83(6.70)$ & $140.73(4.80)$ & $\mathrm{t}(303.12)=4.47$ & $<0.001$ \\
\hline Serum $\mathrm{Cl}^{-}, \mathrm{mmol} / \mathrm{L}$, mean $(\mathrm{SD})$ & $102.22(7.54)$ & $104.21(6.73)$ & $\mathrm{t}(311)=2.36$ & 0.019 \\
\hline Serum $\mathrm{HCO}_{3}{ }^{-}, \mathrm{mmol} / \mathrm{L}$, mean (SD) & $25.38(4.66)$ & $26.14(5.10)$ & $\mathrm{t}(311)=1.34$ & 0.181 \\
\hline \multicolumn{5}{|l|}{$\mathrm{BUN} \geq 19 \mathrm{mg} / \mathrm{dL}$} \\
\hline No & $106(54.4)$ & $20(16.9)$ & $\chi^{2}(1)=42.80$ & $<0.001$ \\
\hline Yes & $89(45.6)$ & $98(83.1)$ & & \\
\hline Serum albumin, g/L, mean (SD) & $27.27(7.10)$ & $27.55(7.10)$ & $\mathrm{t}(311)=0.35$ & 0.731 \\
\hline
\end{tabular}


TA B L E 3. Continued.

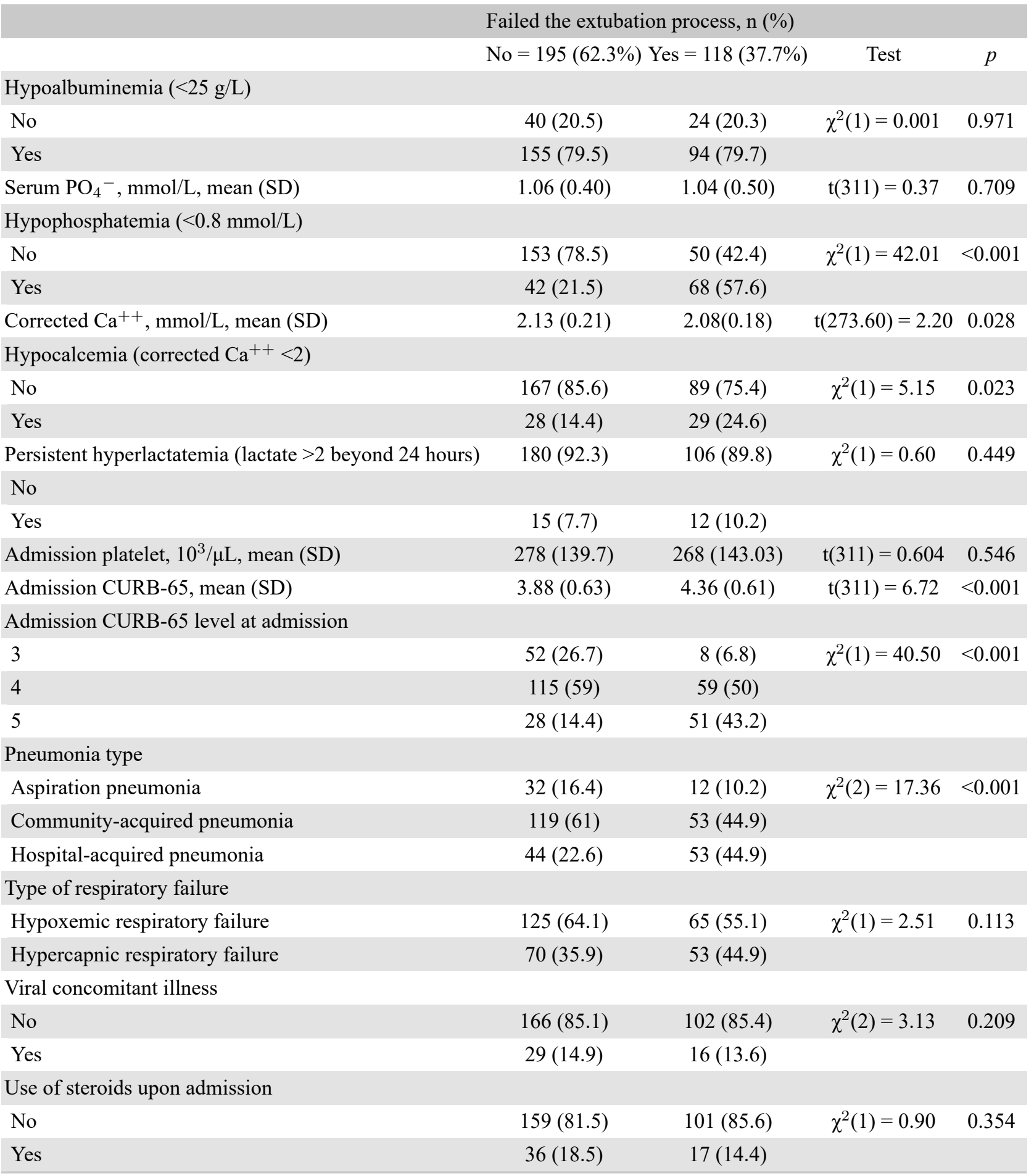

CURB-65, confusion, urea $>7 \mathrm{mmol} \cdot \mathrm{L}-1$, respiratory rate $\geq 30 \cdot \mathrm{min}-1$, low blood pressure, and age $\geq 65$ years; $N a^{+}$, sodium; $\mathrm{Cl}^{-}$, chloride; $\mathrm{HCO3}^{-}$, Bicarbonate; BUN, blood urea nitrogen; $\mathrm{PO}^{-}$, phosphorus; $\mathrm{Ca}^{++}, \mathrm{calcium}^{-} \mathrm{IMV}_{\text {, }}$ invasive mechanical ventilation; $L O S$, length of stay; $S D$, standard deviation; IQR, interquartile range.

* Chi-squared statistic.

** Student's t-test.

*** Mann-whitney U test.

Patients who failed the extubation process had significantly higher mean serum $\mathrm{Na}^{+}(140.73 \pm 4.80)$ and $\mathrm{Cl}^{-}(104.21$ $\pm 6.73)$ at admission than those who were successfully extubated $(137.83 \pm 6.7, p<0.001 ; 102.22 \pm 7.54, p=0.019$, respectively). Patients who presented with a high BUN ( $>19$ $\mathrm{g} / \mathrm{dL}$ ) at admission were also significantly more likely to have extubation failure compared to those with a normal BUN ( $p<$ $0.001)$. No differences were found concerning serum albumin, hypoalbuminemia, persistent hyperlactatemia, platelet count, and serum $\mathrm{PO}_{4}{ }^{-}(p=0.731, p=0.971, p=0.449, p=0.546$, and $p=0.709$, respectively); however, patients who presented with hypophosphatemia were significantly more likely to have 
failed the extubation process than those patients whose serum $\mathrm{PO}_{4}{ }^{-}$was $>0.8 \mathrm{mmol} / \mathrm{L}(p<0.001)$. Patients failed the extubation had also significantly lower mean serum $\mathrm{Ca}^{++}$levels $(2.08 \pm 0.18)$ than patients who had successful extubation $(2.13 \pm 0.21, p=0.028)$; however, hypocalcemic patients at admission (with serum $\mathrm{Ca}^{++}<2 \mathrm{mmol} / \mathrm{L}$ ) were significantly more likely to have failed the extubation process compared to those with a serum $\mathrm{Ca}^{++}>2 \mathrm{mmol} / \mathrm{L}$ at admission $(p=0.028$; Table 3).

Unsurprisingly, patients who failed the extubation presented with higher mean CURB65 scores $(4.36 \pm 0.61)$ compared to their counterparts $(3.88 \pm 0.63 ; p<0.001)$. Further, patients who scored 5 on the CURB65 were significantly more likely to have failed the extubation process compared to those who scored 3 or 4 ( $p<0.001)$. Furthermore, those who failed the extubation tend to have escalating vasopressor requirements beyond 24 hours $(44.1 \%$ vs. $23.6 \% ; p=0.0002)$. Patients who presented with hospital-acquired pneumonia were also significantly more likely to have failed extubation compared to those who presented with community- or aspiration-acquired pneumonia $(p<0.001$; Table 3$)$. Furthermore, the type of respiratory failure and the concomitant viral illness as well as the use of steroids did not correlate significantly with the risk of extubation failure.

The multivariate logistic binary regression analysis was significant overall, denoting that one or more of the tested predictors had a significant association with the extubation failure (Table 4). Patients' sex correlated significantly with their odds of failing the extubation process $(p=0.033)$; although, men were significantly less likely to be re-intubated than women and patients' age did not converge significantly with their odds of failing the extubation. Further, the analysis model indicated that the interaction between patients age and sex suggested that older men compared to younger women were significantly more likely to fail extubation $(\mathrm{OR}=1.21 ; 95 \%$ CI, $1.03-1.22 ; p=0.006$ ). Fig. 2 reveals that after the age of 44 years, men were significantly more likely than women to have required reintubation; conversely, younger women aged $<44$ years were significantly more likely to require an endotracheal reintubation than young men aged $<44$ years. The analysis model also indicated that patients with DM were significantly more likely to have extubation failure $(\mathrm{OR}=3.05$; $95 \% \mathrm{CI}$, $1.22-7.62 ; p=0.017)$.

In addition, patients with a history of cardiac disease were significantly more likely to have extubation failure $(\mathrm{OR}=2.64$; $95 \%$ CI, $1.11-6.3 ; p=0.028)$. The duration of mechanical ventilation also converged significantly on their odds of requiring reintubation. For each additional day on mechanical ventilation, the odds of patients failing the extubation process increased by 1.35 times (i.e., was 35\% times higher; $p<$ 0.001 ). Moreover, $\mathrm{Na}^{+}$level at admission converged significantly and positively with the odds of extubation failure $(p<0.001)$. Nonetheless, chloride level at admission did not correlate significantly with patients' odds of failing the extubation process $(p=0.13)$.

Patients with high BUN scores $(>19 \mathrm{mg} / \mathrm{dL})$ were significantly more likely to fail the extubation $(\mathrm{OR}=2.62 ; 95 \% \mathrm{CI}$, $1.08-6.33 ; p=0.033$ ), and hypophosphatemia at admission significantly predicted higher odds of failing extubation (OR

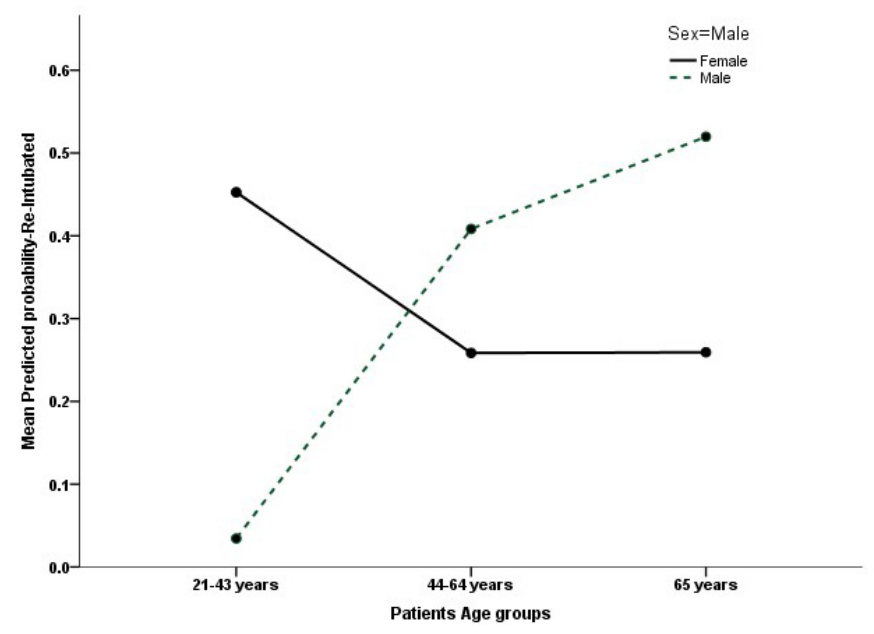

F I G U RE 2. The association between age-sex interaction and the probability of extubation failure among patients with pneumonia.

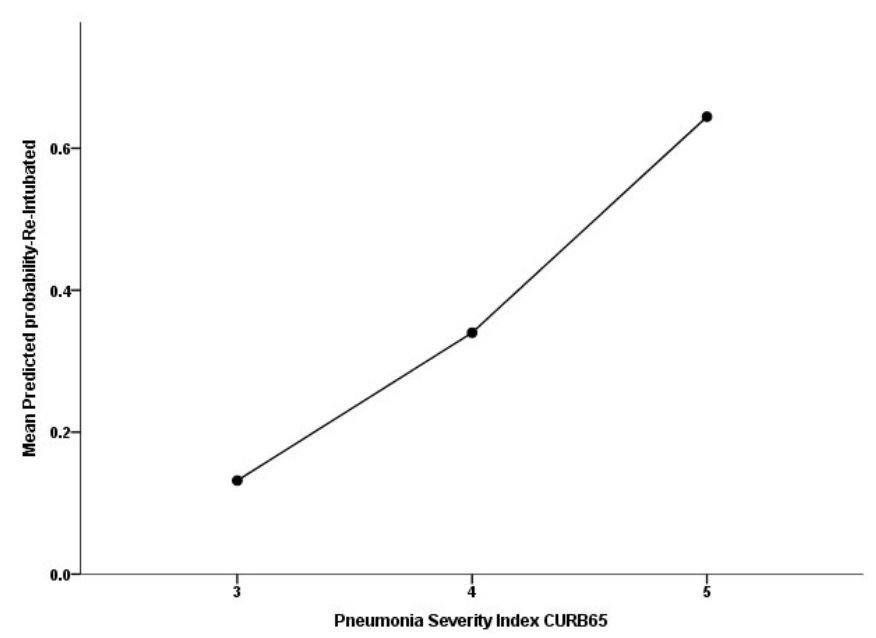

FIGURE 3. The association between the severity of pneumonia using CURB-65 and the probability of extubation failure. CURB-65, confusion, urea $>7 \mathrm{mmol} \cdot \mathrm{L}-1$, respiratory rate $\geq 30 \cdot \mathrm{min}-1$, low blood pressure, and age $\geq 65$ years.

$=2.39 ; 95 \%$ CI, $1.12-5.08 ; p=0.024)$. Nonetheless, patients' CURB-65 score correlated significantly and positively with their odds of failing the extubation process: for every increase on the CURB-65, the odds of failing the extubation trial increased by 3.1 times $(\mathrm{OR}=3.05 ; 95 \% \mathrm{CI}, 1.43-6.52$; $p=0.0040$ ) (Fig. 3). Patients with hypercapnic respiratory failure were more likely $(\mathrm{OR}=1.99)$ to be re-intubated in the ICU compared to those who had hypoxemic respiratory failure; however, the difference was not significant $(p=0.090)$. Lastly, patients who had hospital-acquired pneumonia were significantly more likely to have extubation failure $(\mathrm{OR}=5.90$; 95\% CI, 2.49-13.98; Fig. 4) compared to the patients who presented with community- and aspiration-acquired pneumonia $(p$ $<0.001)$. 
TA B L E 4. Multivariate logistic binary regression analysis of patients' odds of failing the extubation process and requiring reintubation $(\mathrm{N}=313)$.

\begin{tabular}{|lccccc} 
& & \multicolumn{5}{c}{$95 \%$ confidence interval } \\
\hline Sex $=$ male & Beta coefficient & Adjusted odds ratio & Lower & Upper & $p$ \\
\hline Age (years) & -5.643 & 0.004 & 0.000 & 0.638 & $0.033^{*}$ \\
\hline Sex $\times$ Age interaction & -0.036 & 0.965 & 0.909 & 1.024 & 0.242 \\
\hline Diabetes & 0.114 & 1.121 & 1.034 & 1.216 & $0.006^{*}$ \\
\hline History of cardiac disease & 1.115 & 3.050 & 1.221 & 7.619 & $0.017^{*}$ \\
\hline Hemodynamic instability $>24$ hours & 0.972 & 2.643 & 1.109 & 6.298 & $0.028^{*}$ \\
\hline IMV duration (days) & 1.225 & 3.507 & 1.494 & 8.232 & $0.004^{*}$ \\
\hline Serum $\mathrm{Na}^{+}$level at admission & 0.299 & 1.349 & 1.219 & 1.493 & $<0.001^{*}$ \\
\hline Serum $\mathrm{Cl}^{-}$level at admission & 0.363 & 1.437 & 1.250 & 1.653 & $<0.001^{*}$ \\
\hline BUN $>19$ mg/dL at admission & -0.207 & 0.813 & 0.733 & 0.903 & 0.13 \\
\hline Hypophosphatemia & 0.961 & 2.616 & 1.081 & 6.327 & $0.033^{*}$ \\
\hline Hypocalcemia & 0.870 & 2.387 & 1.121 & 5.082 & $0.024^{*}$ \\
\hline CURB-65 score & 1.169 & 3.219 & 1.301 & 7.966 & $0.011^{*}$ \\
\hline Hypercapnic respiratory failure & 1.117 & 3.054 & 1.431 & 6.521 & $0.004^{*}$ \\
\hline Pneumonia type $=$ hospital-acquired & 0.687 & 1.988 & 0.897 & 4.405 & 0.090 \\
\hline Constant & 1.774 & 5.894 & 2.486 & 13.976 & $<0.001^{*}$ \\
\hline
\end{tabular}

Dependent variable $=$ failed extubation $(0=$ no, $1=$ yes $)$. Model's overall significance $=\chi^{2}(16)=187.3, p<0.001 ;$ Model $H$-L chi-squared goodness-of-fit test $=\chi^{2}(8)=26.91, p=0.079 ;$ Model area under the receiver operating characteristic curve $=91 \%$.

$I M V$, invasive mechanical ventilation; $\mathrm{Na}^{+}$, sodium; $\mathrm{Cl}^{-}$, chloride; $\mathrm{BUN}$, blood urea nitrogen; $\mathrm{CURB-65}$, confusion, urea $>7$ mmol.L-1, respiratory rate $\geq 30 \cdot \mathrm{min}-1$, low blood pressure, and age $\geq 65$ years.

*Significant p-value $<0.05$.

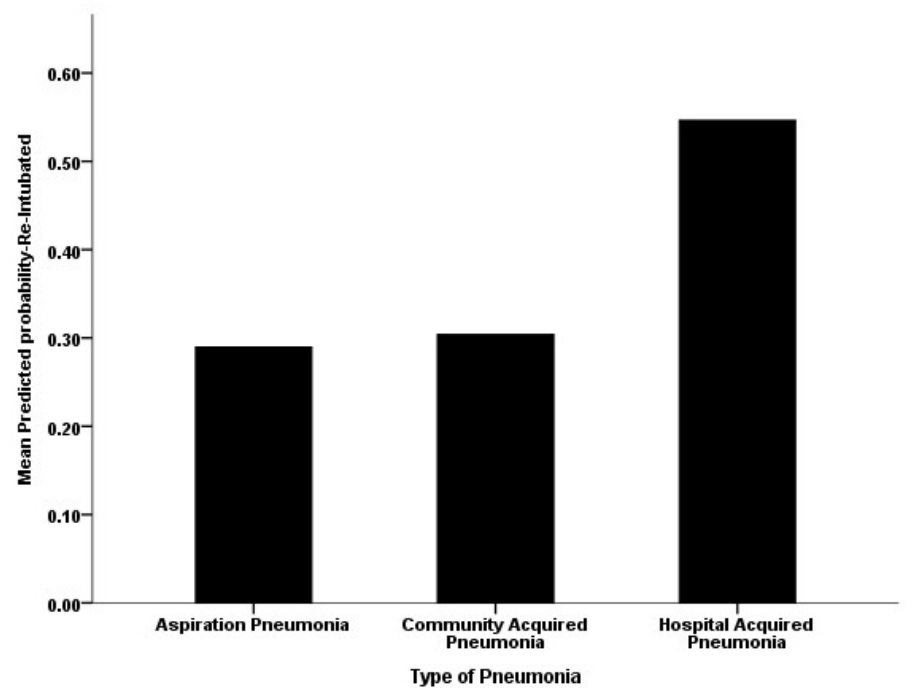

F I G URE 4. The association between the type of pneumonia and the model predicted probability of extubation failure. *Hospital-acquired pneumonia carries a higher risk of non-airway extubation failure higher than communityacquired pneumonia and aspiration pneumonia.

\section{Discussion}

Extubation failure is linked to increased mortality and longer hospital and ICU stay. Owing to the alarming incidence of extubation failure and associated mortality, we explored potential physiological and biochemical factors to identify predictors of extubation failure with an aim to improve patients' outcomes. The current study identified that these predetermined factors could have potential role in reducing the physiological reserve in these patients considering the disease course in ICU and explored the independent risk factors in which the intrinsic capacity to sustain the liberation from IMV is markedly impacted and have led to extubation failure [23].

The current study used a BWAP assessment checklist as exclusion/inclusion criteria (i.e., we excluded all patients scoring $<50$ on the BWAP). The BWAP was designed to facilitate clinicians in evaluation of 26 clinical factors associated with weaning [24]. BWAP - a comprehensive, efficient, and systematic checklist and scoring tool-assists in the management of patients who require long-term mechanical ventilation. Its sensitivity and specificity were $82 \%$ and $55 \%$, respectively; although, sensitivity and specificity levels vary with cut off values [24-26].

Cardiac patients are prone to weaning failure; the first stage of extubation, owing to burden upon cardiovascular system as transition from positive-pressure ventilation to spontaneous breathing occurs [27]. Cardiac function has been previously associated with extubation failure but not in patients with pneumonia. It was reported that, nor the cardiac function or myocardial inflammatory markers are associated with extuba- 
tion failure in severe patients with pneumonia [28]. However, Thille and colleagues and Vallverdu and colleagues identified chronic cardiorespiratory disease and acute respiratory failure of respiratory origin as risk factors for extubation failure [29, 30]. In accordance many prior studies, we reported that an underlying cardiac disease in patients with pneumonia is an independent predictor of extubation failure [7, 31-33].

Furthermore, while identifying the association between demographic factors and extubation failure, Rady and colleagues reported age as an independent predictor for extubation failure, while Thille and colleagues and Vallverdu and colleagues reported age as a risk factor for extubation failure [29, 30, 33]. However, Jaber and colleagues and Suraseranivong and colleagues reported no association between age and extubation failure [9, 34].

Severe hypophosphatemia was associated with respiratory failure; however, the association between phosphate concentration and extubation failure in patients with pneumonia has not been previously studied. Alsumrain and colleagues reported the association between hypophosphatemia and weaning failure; however, predictors of weaning differ from those of extubation failure [35]. The importance of hypophosphatemia in extubation failure and weaning failure lies in the fact that it can lead to respiratory failure owing to impaired diaphragmatic contractility [36]. Respiratory insufficiency can be due to insufficient 2,3-diphosphoglycerate production, leading to a significant change in hemoglobin dissociation curve and weakness in respiratory muscles, which is a common manifestation of hypophosphatemia [37]. Higher sodium is also a poor predictor for extubation failure, especially among elderly patients, which may reflect the illness severity in this group [34, 38]. Our study showed that patients who failed extubation had higher sodium levels compared to those who were successfully extubated, regardless of their age.

CURB-65 score was used to assess the disposition among patients with pneumonia. CURB-65 is a mortality prediction scoring system for community-acquired pneumonia (confusion, urea $>7 \mathrm{mmol} \cdot \mathrm{L}-1$, respiratory rate $\geq 30 \cdot \mathrm{min}-1$, low blood pressure, and age $\geq 65$ years) [39]. Since the CURB65 score reflects the severity of pneumonia, it could be a good tool to reflect on the impact that the disease may have on the physiological reserve. In this study, CURB65 was an independent risk factor for extubation failure. We also found that increased time for intubation and increased length of stay in the ICU may also serve as predictors of extubation failure in patients with pneumonia, which are also associated with illness severity and hence CURB-65 score.

The limitations of this study need to be acknowledged. Although the study has a relatively large sample size, the study is retrospective in nature. The acute factors and baseline characteristics could be more explored that could be potential confounders for this study. Functional status of the patients was not determined. Objective functional assessment of physiological reserve and incorporating frailty scores would add to the values of the study although some comorbidities might have indicated otherwise. Other indicators on this admission such as the course of the disease during the ICU and potential complications were not considered. Furthermore, body measurements such as waist circumference and hip-waist ratios and their interaction with the mechanical ventilator in the context of the functional status as opposed to the BMI would have added more values on this study. Other important consideration to the weaning success was not considered such as fluid balance and the availability of such information would have validated the results more. Future randomized controlled trials emphasizing the effect of the physiological reserve and sustainability from IMV on the extubation failure rather than the successful weaning score are needed.

\section{Conclusions}

Admission-acute factors including the duration of IMV, type of pneumonia, severity of pneumonia, the hemodynamic instability, and patterns of electrolytes; along with baseline factors including the age - sex interaction, history of diabetes mellitus, and history of cardiac disease can strongly predict nonairway extubation failure in patients with pneumonia with high successful weaning scores. Such factors are useful surrogate characteristics that reflect the physiological reserve and the ability to sustain the liberation from IMV. Sustainability from IMV scores for prolonged intubation based on the physiological reserve is imperative and more reflective on extubation failure than simple successful weaning score.

\section{Highlights}

High successful weaning score could be misleading for extubation success in patients with pneumonia.

Including factors reflecting the physiological reserve in patients with pneumonia with a high weaning successful weaning score could be useful to determine successful extubation.

"Sustainability from IMV" scores could be more predictive of extubation failure than weaning scores.

\section{AUTHOR CONTRIBUTIONS}

RMQ: Conceptualization, methodology, writing and editing, and supervision. YKA, SAA: Data curation, investigation, and validation. BAZ, HKA, KWA, MYA: Data curation, and original draft preparation. MIA, AA: Formal analysis, review and editing.

\section{ETHICS APPROVAL AND CONSENT TO PARTICIPATE}

The study design was approved by the Institutional Review Board of the health science colleges at King Saud University (E-19-4221).

\section{ACKNOWLEDGMENT}

We would like to thank the department of Critical Care Medicine and the department of Medicine at King Saud University for their valuable help and support. We would like to thank the peer reviewers for their opinions and suggestions. 


\section{FUNDING}

This research received no external funding.

\section{CONFLICT OF INTEREST}

The authors declare no conflict of interest.

\section{REFERENCES}

[1] Epstein SK, Ciubotaru RL, Wong JB. Effect of failed extubation on the outcome of mechanical ventilation. Chest. 1997; 112: 186-192.

[2] Miller RL, Cole RP. Association between reduced cuff leak volume and postextubation stridor. Chest. 1996; 110: 1035-1040.

[3] Esteban A, Frutos F, Tobin MJ, Alía I, Solsona JF, Valverdu V, et al. A comparison of four methods of weaning patients from mechanical ventilation. New England Journal of Medicine. 1995; 332: 345-350.

[4] Luo J, Yu H, Ni Y, Hu Y, Liu D, Wang M, et al. Early prediction of extubation failure in severe pneumonia: a retrospective cohort study. Acute Critical Care. 2020; 40: BSR20192435.

[5] Seymour CW, Martinez A, Christie JD, Fuchs BD. The outcome of extubation failure in a community hospital intensive care unit: a cohort study. Critical Care. 2004; 8: R322-R327.

[6] Agarwal V. Extubation failure in intensive care unit: predictors and management. Indian Journal of Critical Care Medicine. 2008; 12: 1-9.

[7] Epstein SK, Ciubotaru RL. Independent effects of etiology of failure and time to reintubation on outcome for patients failing extubation. American Journal of Respiratory and Critical Care Medicine. 1998; 158: 489-493.

[8] Frutos-Vivar F, Ferguson ND, Esteban A, Epstein SK, Arabi Y, Apezteguía $\mathrm{C}$, et al. Risk factors for extubation failure in patients following a successful spontaneous breathing trial. Chest. 2006; 130: $1664-1671$.

[9] Jaber S, Quintard H, Cinotti R, Asehnoune K, Arnal J, Guitton C, et al. Risk factors and outcomes for airway failure versus non-airway failure in the intensive care unit: a multicenter observational study of 1514 extubation procedures. Critical Care. 2018; 22: 236.

[10] Tu C, Chang C, Chang S, Lee C, Chang C. A decision for predicting successful extubation of patients in intensive care unit. BioMed Research International. 2018; 2018: 6820975.

[11] Thille AW, Richard JM, Brochard L. The decision to extubate in the intensive care unit. American Journal of Respiratory and Critical Care Medicine. 2013; 187: 1294-1302.

[12] Carpio ALM, Mora JI. Ventilator management. StatPearls Publishing. 2019. Available from: https://www.statpearls.com/ ArticleLibrary/viewarticle/31075

[13] Zein H, Baratloo A, Negida A, Safari S. Ventilator weaning and spontaneous breathing trials; an educational review. Emergency. 2016; 4: 65-71.

[14] Subirà C, Hernández G, Vázquez A, Rodríguez-García R, GonzálezCastro A, García C, et al. Effect of pressure support vs T-piece ventilation strategies during spontaneous breathing trials on successful extubation among patients receiving mechanical ventilation: a randomized clinical trial. Journal of the American Medical Association. 2019; 321: 2175-82.

[15] Fernando SM, McIsaac DI, Rochwerg B, Bagshaw SM, Muscedere J, Munshi L, et al. Frailty and invasive mechanical ventilation: association with outcomes, extubation failure, and tracheostomy. Intensive Care Medicine. 2019; 45: 1742-1752.

[16] Ince C. Personalized physiological medicine. Critical Care. 2017; 21: 308.

[17] Bayliss EA, Ellis JL, Steiner JF. Subjective assessments of comorbidity correlate with quality of life health outcomes: initial validation of a comorbidity assessment instrument. Health and Quality of Life Outcomes. 2005; 3: 51.

[18] Sellares J, Ferrer M, Cano E, Loureiro H, Valencia M, Torres A. Predictors of prolonged weaning and survival during ventilator weaning in a respiratory ICU. Intensive Care Medicine. 2011; 37: 775-784.

[19] Peña-López Y, Ramirez-Estrada S, Eshwara VK, Rello J. Limiting ventilator-associated complications in ICU intubated subjects: strategies to prevent ventilator-associated events and improve outcomes. Expert Review of Respiratory Medicine. 2018; 12: 1037-1050.

[20] Alía I, Esteban A. Weaning from mechanical ventilation. Critical Care. 2000; 4: 72-80.

[21] Burns SM, Fisher C, Earven Tribble SS, Lewis R, Merrel P, Conaway $\mathrm{MR}$, et al. Multifactor clinical score and outcome of mechanical ventilation weaning trials: burns wean assessment program. American Journal of Critical Care: An Official Publication, American Association of Critical-Care Nurses. 2010; 19: 431-439.

[22] Boles J, Bion J, Connors A, Herridge M, Marsh B, Melot C, et al. Weaning from mechanical ventilation. The European Respiratory Journal. 2007; 29: 1033-1056.

[23] Chhetri JK, Xue QL, Ma L, Chan P, Varadhan R. Intrinsic capacity as a determinant of physical resilience in older adults. Journal of Nutrition Health \& Aging. 2021; 1-6.

[24] Burns SM, Fisher C, Tribble SES, Lewis R, Merrel P, Conaway MR, et $a l$. The relationship of 26 clinical factors to weaning outcome. American Journal of Critical Care. 2012; 21: 52-59.

[25] Jeong ES, Lee K. Clinical application of modified burns wean assessment program scores at first spontaneous breathing trial in weaning patients from mechanical ventilation. Acute and Critical Care. 2018; 33: 260268.

[26] Burns SM, Marshall M, Burns JE, Ryan B, Wilmoth D, Carpenter R, et al. Design, testing, and results of an outcomes-managed approach to patients requiring prolonged mechanical ventilation. American Journal of Critical Care. 1998; 7: 45-49.

[27] Vignon P. Cardiovascular failure and weaning. Annals of Translational Medicine. 2018; 6: 354.

[28] Yu H, Luo J, Ni Y, Hu Y, Liu D, Wang M, et al. Early prediction of extubation failure in patients with severe pneumonia: a retrospective cohort study. Bioscience Reports. 2020; 40: BSR20192435

[29] Thille AW, Harrois A, Schortgen F, Brun-Buisson C, Brochard L. Outcomes of extubation failure in medical intensive care unit patients. Critical Care Medicine. 2011; 39: 2612-2618.

[30] Vallverdú I, Calaf N, Subirana M, Net A, Benito S, Mancebo J. Clinical characteristics, respiratory functional parameters, and outcome of a two-hour T-piece trial in patients weaning from mechanical ventilation. American Journal of Respiratory and Critical Care Medicine. 1999; 158: 1855-1862.

[31] Lee KH, Hui KP, Chan TB, Tan WC, Lim TK. Rapid shallow breathing (frequency-tidal volume ratio) did not predict extubation outcome. Chest. 1994; 105: 540-543.

[32] Capdevila XJ, Perrigault PF, Perey PJ, Roustan JP, d'Athis F. Occlusion pressure and its ratio to maximum inspiratory pressure are useful predictors for successful extubation following T-piece weaning trial. Chest. 1995; 108: 482-489.

[33] Rady MY, Ryan T. Perioperative predictors of extubation failure and the effect on clinical outcome after cardiac surgery. Critical Care Medicine. 1999; 27: 340-347.

[34] Suraseranivong R, Krairit O, Theerawit P, Sutherasan Y. Association between age-related factors and extubation failure in elderly patients. PLoS ONE. 2018; 13: e0207628.

[35] Alsumrain MH, Jawad SA, Imran NB, Riar S, DeBari VA, Adelman M. Association of hypophosphatemia with failure-to-wean from mechanical ventilation. Annals of Clinical and Laboratory Science. 2010; 40: 144 148.

[36] Aubier M, Murciano D, Lecocguic Y, Viires N, Jacquens Y, Squara P, et al. Effect of hypophosphatemia on diaphragmatic contractility in patients with acute respiratory failure. New England Journal of Medicine. 1985; 313: 420-424.

[37] Dooley J, Fegley A. Laboratory monitoring of mechanical ventilation. Critical Care Clinics. 2007; 23: 135-48.

[38] Kohno S, Seki M, Takehara K, Yamada Y, Kubo K, Ishizaka A, et $a l$. Prediction of requirement for mechanical ventilation in communityacquired pneumonia with acute respiratory failure: a multicenter prospective study. Respiration. 2013; 85: 27-35.

[39] Ilg A, Moskowitz A, Konanki V, Patel PV, Chase M, Grossestreuer $\mathrm{AV}$, et al. Performance of the CURB- 65 score in predicting critical care interventions in patients admitted with community-acquired pneumonia. Annals of Emergency Medicine. 2019; 74: 60-68. 
How to cite this article: Rakan M. AlQahtani, Yasmeen Khalaf Altaymani, Saud Ali Aljasir, Bader Abdulaziz Zawawi, Hisham Khaled Algossy, Khalid Waleed Alhusainan, et al. The effect of the physiological reserve surrogate characteristics on non-airway extubation failure in patients with pneumonia with high Burns wean assessment program scores. Signa Vitae. 2021;17(6):90102. doi:10.22514/sv.2021.094. 